\title{
Concepção de ferramentas de percepção, representando dados do fluxo de atividades discentes em ambiente colaborativo de aprendizagem.
}

\author{
Paulo A. R. Perris ${ }^{1}$, Rodrigo Lins Rodrigues ${ }^{2}$, Alex Sandro Gomes ${ }^{1}$ \\ ${ }^{1}$ Centro de Informática - Universidade Federal de Pernambuco \\ 2Departamento de Educação - Universidade Federal Rural de Pernambuco \\ parp@cin.ufpe.br, rlr@ded.ufrpe.br, asg@cin.ufpe.br
}

\begin{abstract}
We seek to understand, throughout the article, such activities can assist in student collaboration. We used techniques of task analysis, analysis of interactions in the network environment. This article examines the use of existing data in the logs of the achievements of student activities in LMS environments as a tool for collaboration and learning. Preliminary results point to successes and needs for undiagnosed at conception LMS and guide us in the design of tools for collaborative learning.
\end{abstract}

Resumo. Buscamos compreender, no decorrer do artigo, como as atividades podem auxiliar na colaboração dos alunos. Utilizou-se de técnicas de análise da tarefa, análise das interações no ambiente da rede. Este artigo analisa o uso dos dados existentes nos logs das realizações das atividades discentes em ambientes LMS como ferramenta de colaboração e aprendizado. Os resultados preliminares apontam para acertos e para necessidades não diagnosticadas no momento da concepção do LMS e nos orientam na concepção de ferramentas para aprendizado colaborativo.

\section{Introdução}

Em um LMS, o conhecimento é distribuído através de pessoas e objetos e inclui as interações entre as pessoas com os recursos e materiais no meio ambiente. $\mathrm{O}$ sentido participativo que os alunos fazem para coordenar uma atividade em que haja interação, e que cada processo de tomada de decisões é afetado, transformando o conhecimento em novos domínios de sentido social gerado, onde antes não estavam disponíveis para cada indivíduo em si é, particularmente, valioso em um ambiente interligado [DE JAEGHER e DI PAOLO, 2008].

A plataforma Amadeus LMS foi a ferramenta que serviu para auxiliar professores e alunos na construção do conhecimento. Para atingir esse objetivo buscouse conceber e testar estilos de interação colaborativos que permitissem aos alunos ajudarem-se entre si, além de identificar práticas de colaboração existentes entre os mesmos.

Este artigo está organizado da seguinte forma. Na seção 2 é apresentado o referencial sobre o aprendizado colaborativo em LMS. Na seção 3 é apresentado o método de concepção e desenvolvimento da solução proposta. A seção 4 mostra os 
resultados obtidos e testes com usuários. A seção 5 mostra as considerações finais e conclusões do trabalho.

\section{Aprendizado Colaborativo}

Há hoje esforços de pesquisa e desenvolvimento para dar suporte às diversas interações, à colaboração e ao compartilhamento de informações entre membros de um grupo em ambientes LMS [UZUNBOYLU, BICEN e CAVUS, 2011]. Uma dessas áreas de pesquisa é a Aprendizagem Colaborativa Apoiada por Computador (do inglês Computer-Supported Colaborative Learning, ou apenas CSCL), que surgiu com a finalidade de proporcionar um ambiente colaborativo, centrado na aprendizagem, dando origem a diversos LMS que apoiam os processos de aprendizagem promovidos através de esforços colaborativos [DILLENBOURG e HONG, 2008].

Dentro dessa área, o tema de coordenação e percepção de pequenos grupos aborda que princípios de aprendizagem colaborativa podem ser aplicados a ambientes educacionais e às atribuições das equipes aos alunos mais experientes ou com maior domínio da disciplina [LUVIZOTTO, FUSCO e SCANAVACCA, 2010].

Com o amadurecimento da prática da Educação a Distância, o desafio não é a utilização de novas tecnologias para recriar os sistemas tradicionais de ensino, mas sim criar novos ambientes de aprendizagem, proporcionando melhorias para professores e alunos, e melhorar a qualidade da educação [DILLENBOURG e HONG, 2008].

\section{Método}

Os dados pesquisados foram obtidos nas práticas e interações dos sujeitos em situação real e, portanto, o planejamento do método de pesquisa buscou ser suficientemente aberto para fazer justiça à complexidade em questão, o que vem a justificar, segundo Preece, Rogers e Sharp (2005) a escolha pela análise qualitativa para o design.

O presente trabalho mostra a adoção de ferramentas de percepção, representando dados do fluxo das atividades discentes, integrados ao LMS Amadeus, capazes de tornarem mais eficazes a resolução destas atividades por parte dos discentes com pouca experiência em cursos mediados por tecnologias, proporcionando o aprendizado colaborativo.

\subsection{Participantes}

Como participantes desta pesquisa, foram convidados professores doutores em educação e em inovação educativa e alunos matriculados no mestrado do EDUMATEC ${ }^{1}$.

Nesta pesquisa, foram entrevistados alunos e professores participantes da disciplina de introdução a educação a distância. Dentre os vinte e cinco participantes da disciplina inserida no contexto desta pesquisa, foram selecionados dez alunos e dois professores, para a aplicação de uma entrevista semiestruturada, buscando levantar o grau de conhecimento sobre a usabilidade de ambientes LMS e as necessidades de implementações nestes.

Durante a pesquisa, percebeu-se que quase $1 / 4$ de sua carreira acadêmica dos participantes já é destinada também a prática de educação mediada por tecnologia.

\footnotetext{
${ }^{1}$ Programa de Educação Matemática e Tecnológica, Centro de Educação - CE - UFPE
} 


\subsection{Coletas e Análise de dados}

O experimento foi dividido em três etapas: a primeira etapa e segunda etapa, realizada no segundo semestre de 2010 e de 2011, foi composta observação de como os participantes interagiam no ambiente para a resolução das atividades. Todos os apontamentos da primeira e segunda etapa foram trazidos para a terceira etapa no segundo semestre de 2012, com fins de comparação das necessidades dos usuários dos anos anteriores, com as necessidades dos alunos deste ano.

Para a análise e categorização dos dados foi utilizado o software de análise qualitativa NVivo ${ }^{2}$. Auxiliando na categorização dos dados, relacionando-os e ajudando na elaboração da hierarquização em forma de árvore.

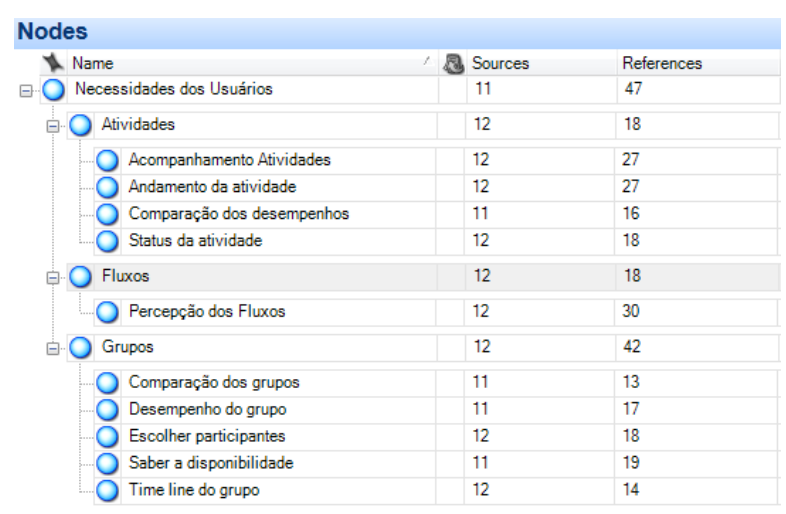

Figura 1 - Analise dos dados das entrevistas e necessidades dos usuários.

\subsection{Prototipação}

Com a identificação e o levantamento dos novos requisitos, foram prototipadas telas para identificação de novas formas de uso no Amadeus. A prototipação foi feita através do software Balsamiq ${ }^{3}$. As alterações foram incorporadas de acordo com o levantamento de requisitos que foram elicitados durante todo o processo já mencionado. Enfatizando as reais necessidades que foram expressas pelos usuários.

\section{Resultados e Discussão}

Nesta seção, apresentaremos os resultados acerca da estrutura da colaboração, e das formas de interação durante o uso do Amadeus pelos participantes do experimento.

\subsection{Requisitos associados}

Os requisitos mostrados abaixo, originados pelas necessidades apontadas pelos usuários, foram usados na pesquisa de campo, aplicados na prototipagem e nos storyboards, para comprovação de sua eficácia.

\begin{tabular}{|l|l|}
\hline Requisitos Funcionais & Requisitos não funcionais \\
\hline Listar usuários cadastrados no curso & Indicar integrantes adicionados em outros grupos \\
\hline Log de acessos & Status da atividade (Usuário) \\
\hline Andamento das atividades & Dar percepção ao desempenho ou participação do grupo \\
\hline
\end{tabular}

\footnotetext{
${ }^{2}$ NVivo é um software que suporta métodos de pesquisa qualitativos e mistos.

${ }^{3}$ Aplicativo utilizado para prototipação de telas em baixa e média fidelidade.
} 


\subsection{Prototipagem}

O processo de prototipagem fez parte do ciclo de desenvolvimento de Design de Interação, sendo utilizado para antecipar ao usuário final características da interface que poderiam ser testadas, validadas e modificadas pelos stakeholders.

\subsection{Storyboard}

A técnica correspondeu ao detalhamento de um cenário de uso especificado para o sistema, consistindo em uma sequência de desenhos representando não só esboços de telas, mas também elementos do contexto.

Depois de explicar a ideia básica de padrões para os usuários, deu-se um roteiro para o que precisava ser capturado na simulação, observando mais explicitamente problemas, dando força aos apontamentos das soluções existentes, e referências dentro desses padrões de trabalho.

Para saber se as atividades postas na semana estavam sendo realizadas, primeiro acessa-se a opção visualizar grupos.

Ao se visualizar os grupos, já se tem a percepção de que as atividades estão ou não sendo realizadas pelos grupos, sinalizadas em seus status por verde (concluída) ou vermelho (a concluir).
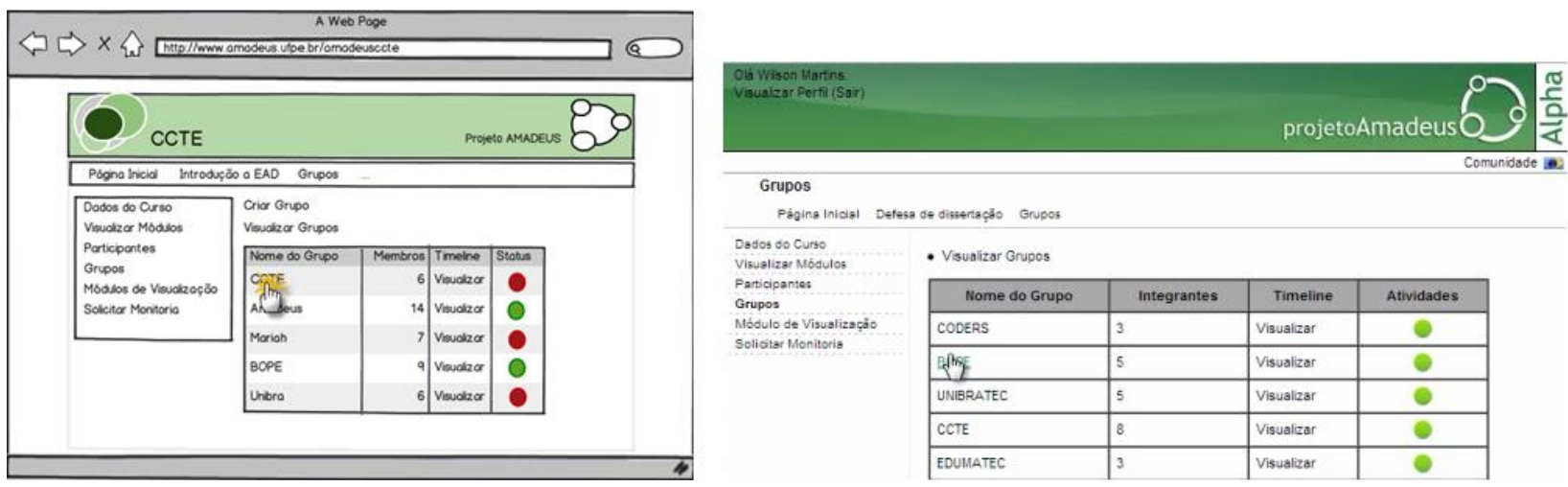

Figura 3 - Prototipagem e produto: Escolher grupo a ser visualizado.

Caso o aluno que ainda não fez a sua atividade queira saber como outro integrante do seu grupo fez, clica no nome do integrante e será mostrado o $\log$ da realização da atividade (Figura 5).
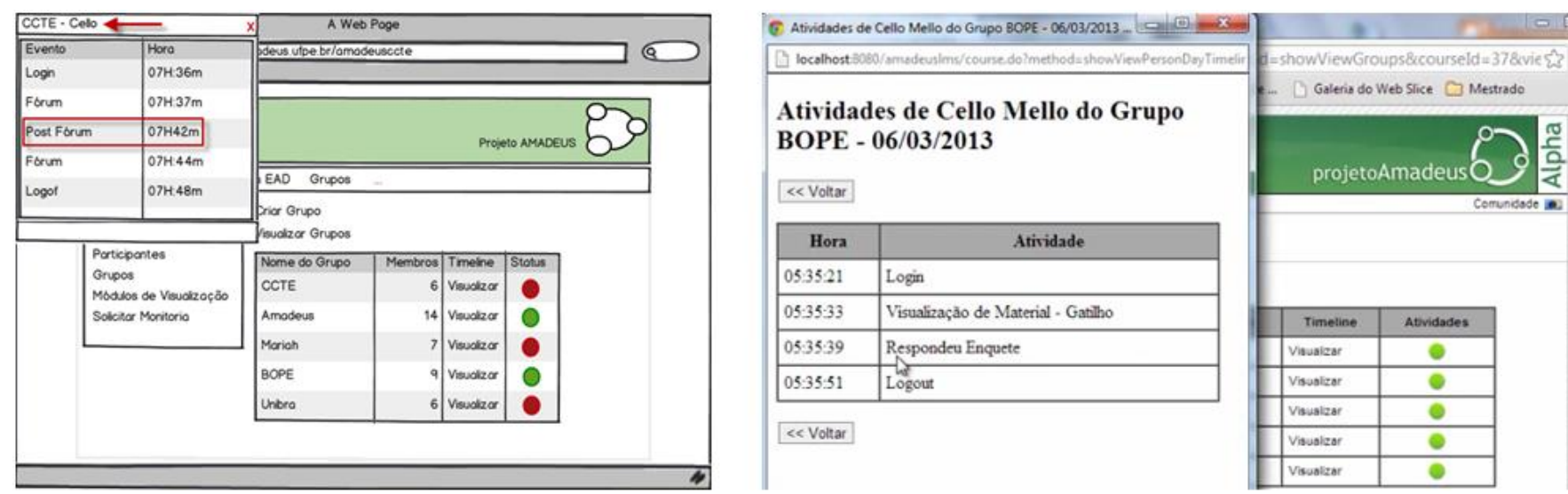

Figura 2 - Prototipagem e produto: Visualizar log da atividade discente. 


\subsection{Discussão}

Para que ocorra um aprendizado colaborativo é necessário que exista interação entre todos os envolvidos [DILLENBOURG e HONG, 2008]. Neste aspecto, a eficiência da colaboração no Amadeus deu, na opinião dos participantes, um maior aprendizado colaborativo que os mesmos acreditam poder existir nos ambientes LMS.

$\checkmark$ Aluno 9 - Acredito que percebendo como outro aluno fez para resolver as atividades dele no ambiente eu possa me guiar para responder a minha, já que tenho pouca experiência em $\mathrm{EaD}$.

$\checkmark$ Professor 1 - É importante que o aluno interaja mais no ambiente, porém temos que ter o controle sobre suas ações. Poder editar a qualquer momento, corrigindo eventuais erros é uma opção a mais na ajuda da coordenação do ambiente.

\section{Considerações Finais}

Este trabalho apresentou conceitos sobre aprendizagem colaborativa e interação em um ambiente LMS, buscando identificar requisitos de interação e colaboração. Em nossa proposta foram elucidados novas ferramentas que fazem com que tais aspectos sejam mais eficiente e auxilie o aluno na execução de atividades colaborativas de aprendizagem.

Como resultado obtido na implementação dos registros dos $\operatorname{logs}$ das atividades executadas pelos discentes no ambiente com relação aos módulos disponibilizados pelos professores. Tal geração de $\log$ no Amadeus poderá servir de script para que outro aluno possa seguir, de modo a realizar suas atividades condizendo com as pesquisas de Dellembourg et al.(2011) sobre aprendizado colaborativo e instrumentação de ambientes LMS.

\section{Referencias}

De Jaegher, H., Di Paolo, E. Participatory sense-making: An enactive approach to social cognition. Phenomenology and the Cognitive Sciences, University of Sussex, 2008.

Dillenbourg, P.; Hong, F. The mechanics of CSCL macro scripts. International Journal of Computer-Supported Colaborative Learning, Springer, 2008.

Dillenbourg, P.; Zufferey, G.; Alavi, H.; Jermann, P.; Do-Lenh, S.; Bonnard, Q.; Cuendet, S.; Kaplan, F. Classroom orchestration: The third circle of usability. Proceedings of CSCL. infoscience.epfl.ch, 2011.

Luvizotto,C.K.; Fusco, E.; Scanavacca,A.C. Websites educacionais: considerações acerca da arquitetura da informação no processo de ensino-aprendizagem. Educação em Revista, Marília, 2010.

Preece, J.; Rogers, Y.; Sharp, H. Design de Interação: Além da Interação homemcomputador. Editora Bookman, São Paulo, 2005.

Uzunboylu, H.; Bicen, H.; Cavus, N. The efficient virtual learning environment: A case study of web 2.0 tools and Windows live spaces. Computers \& Education, Elsevier, 2011. 